\title{
Evidence Synthesis Activities of a Hospital Evidence-Based Practice Center and Impact on Hospital Decision Making
}

\author{
Kishore L. Jayakumar, BS¹, Julia A. Lavenberg, PhD², Matthew D. Mitchell, PhD², Jalpa A. Doshi, PhD²,3,4 Brian Leas, MA, MS²,

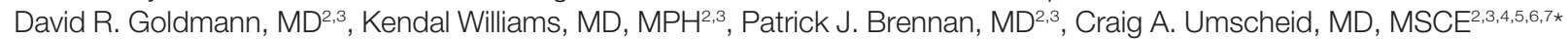

\begin{abstract}
${ }^{1}$ University of Pennsylvania Perelman School of Medicine, Philadelphia, Pennsylvania; ${ }^{2}$ Center for Evidence-based Practice, University of Pennsylvania Health System, Philadelphia, Pennsylvania; ${ }^{3}$ Department of Medicine, University of Pennsylvania Perelman School of Medicine, Philadelphia, Pennsylvania; ${ }^{4}$ Leonard Davis Institute of Health Economics, University of Pennsylvania, Philadelphia, Pennsylvania; 5 Institute for Biomedical Informatics, University of Pennsylvania Perelman School of Medicine, Philadelphia, Pennsylvania; ${ }^{6}$ Department of Biostatistics and Epidemiology, University of Pennsylvania Perelman School of Medicine, Philadelphia, Pennsylvania; ${ }^{7}$ Institute for Translational Medicine and Therapeutics, University of Pennsylvania, Philadelphia, Pennsylvania.
\end{abstract}

BACKGROUND: Hospital evidence-based practice centers (EPCs) synthesize and disseminate evidence locally, but their impact on institutional decision making is unclear.

OBJECTIVE: To assess the evidence synthesis activities and impact of a hospital EPC serving a large academic healthcare system.

DESIGN, SETTING, AND PARTICIPANTS: Descriptive analysis of the EPC's database of rapid systematic reviews since EPC inception (July 2006-June 2014), and survey of report requestors from the EPC's last 4 fiscal years.

MEASUREMENTS: Descriptive analyses examined requestor and report characteristics; questionnaire examined report usability, impact, and requestor satisfaction (higher scores on 5-point Likert scales reflected greater agreement).

RESULTS: The EPC completed 249 evidence reviews since inception. The most common requestors were clinical departments $(29 \%, n=72)$, chief medical officers $(19 \%$, $n=47)$, and purchasing committees $(14 \%, n=35)$. The most common technologies reviewed were drugs $(24 \%$, $n=60)$, devices $(19 \%, n=48)$, and care processes $(12 \%$, $\mathrm{n}=31$ ). Mean report completion time was 70 days. Thirty reports (12\%) informed computerized decision support interventions. More than half of reports $(56 \%, n=139)$ were completed in the last 4 fiscal years for 65 requestors. Of the 64 eligible participants, 46 responded (72\%). Requestors were satisfied with the report (mean $=4.4)$, and agreed it was delivered promptly (mean $=4.4)$, answered the questions posed (mean $=4.3$ ), and informed their final decision $($ mean $=4.1)$.

CONCLUSIONS: This is the first examination of evidence synthesis activities by a hospital EPC in the United States. Our findings suggest hospital EPCs can efficiently synthesize and disseminate evidence addressing a range of clinical topics for diverse stakeholders, and can influence local decision making. Journal of Hospital Medicine 2016;11:185-192. @ 2015 Society of Hospital Medicine
Hospital evidence-based practice centers (EPCs) are "structures" with the potential to facilitate the integration of evidence into institutional decision making to close "knowing-doing" gaps ${ }^{1-6}$; in the process, they can support the evolution of their parent institutions into "learning healthcare systems." 7 The potential of hospital EPCs stems from their ability to identify and adapt national evidence-based guidelines and systematic reviews for the local setting, ${ }^{8}$ create local evidencebased guidelines in the absence of national guidelines, use local data to help define problems and assess the impact of solutions, ${ }^{9}$ and implement evidence into practice through computerized clinical decision support (CDS) interventions and other quality-improvement

*Address for correspondence and reprint requests: Craig A. Umscheid, MD, University of Pennsylvania Health System, 3535 Market Street Mezzanine, Suite 50, Philadelphia, PA 19104; Telephone: 215-349-8098; Fax: 215-349-5829; E-mail: craig.umscheid@uphs.upenn.edu

Additional Supporting Information may be found in the online version of this article.

Received: July 26, 2015; Revised: September 18, 2015; Accepted: September 26, 2015

2015 Society of Hospital Medicine DOI 10.1002/jhm.2498

Published online in Wiley Online Library (Wileyonlinelibrary.com).
(QI) initiatives. ${ }^{9,10}$ As such, hospital EPCs have the potential to strengthen relationships and understanding between clinicians and administrators ${ }^{11}$; foster a culture of evidence-based practice; and improve the quality, safety, and value of care provided. ${ }^{10}$

Formal hospital EPCs remain uncommon in the United States, ${ }^{10-12}$ though their numbers have expanded worldwide. ${ }^{13,14}$ This growth is due not to any reduced role for national EPCs, such as the National Institute for Health and Clinical Excellence ${ }^{15}$ in the United Kingdom, or the 13 EPCs funded by the Agency for Healthcare Research and Quality (AHRQ) ${ }^{16,17}$ in the United States. Rather, this growth is fueled by the heightened awareness that the value of healthcare interventions often needs to be assessed locally, and that clinical guidelines that consider local context have a greater potential to improve quality and efficiency.9,18,19

Despite the increasing number of hospital EPCs globally, their impact on administrative and clinical decision making has rarely been examined, ${ }^{13,20}$ especially for hospital EPCs in the United States. The few studies that have assessed the impact of hospital EPCs on institutional decision making have done so in the context of technology acquisition, neglecting the role 
hospital EPCs may play in the integration of evidence into clinical practice. For example, the Technology Assessment Unit at McGill University Health Center found that of the 27 reviews commissioned in their first 5 years, 25 were implemented, with 6 (24\%) recommending investments in new technologies and 19 $(76 \%)$ recommending rejection, for a reported net hospital savings of $\$ 10$ million. $^{21}$ Understanding the activities and impact of hospital EPCs is particularly critical for hospitalist leaders, who could leverage hospital EPCs to inform efforts to support the quality, safety, and value of care provided, or who may choose to establish or lead such infrastructure. The availability of such opportunities could also support hospitalist recruitment and retention.

In 2006, the University of Pennsylvania Health System (UPHS) created the Center for Evidence-based Practice (CEP) to support the integration of evidence into practice to strengthen quality, safety, and value. ${ }^{10}$ Cofounded by hospitalists with formal training in clinical epidemiology, the CEP performs rapid systematic reviews of the scientific literature to inform local practice and policy. In this article, we describe the first 8 years of the CEP's evidence synthesis activities and examine its impact on decision making across the health system.

\section{METHODS}

\section{Setting}

The UPHS includes 3 acute care hospitals, and inpatient facilities specializing in acute rehabilitation, skilled nursing, long-term acute care, and hospice, with a capacity of more than 1800 beds and 75,000 annual admissions, as well as primary care and specialty clinics with more than 2 million annual outpatient visits. The CEP is funded by and organized within the Office of the UPHS Chief Medical Officer, serves all UPHS facilities, has an annual budget of approximately $\$ 1$ million, and is currently staffed by a hospitalist director, 3 research analysts, 6 physician and nurse liaisons, a health economist, biostatistician, administrator, and librarians, totaling 5.5 full time equivalents.

The mission of the CEP is to support the quality, safety, and value of care at Penn through evidencebased practice. To accomplish this mission, the CEP performs rapid systematic reviews, translates evidence into practice through the use of CDS interventions and clinical pathways, and offers education in evidence-based decision making to trainees, staff, and faculty. This study is focused on the CEP's evidence synthesis activities.

Typically, clinical and administrative leaders submit a request to the CEP for an evidence review, the request is discussed and approved at the weekly staff meeting, and a research analyst and clinical liaison are assigned to the request and communicate with the requestor to clearly define the question of interest. Subsequently, the research analyst completes a protocol, a draft search, and a draft report, each reviewed and approved by the clinical liaison and requestor. The final report is posted to the website, disseminated to all key stakeholders across the UPHS as identified by the clinical liaisons, and integrated into decision making through various routes, including in-person presentations to decision makers, and CDS and QI initiatives.

\section{Study Design}

The study included an analysis of an internal database of evidence reviews and a survey of report requestors, and was exempted from institutional review board review. Survey respondents were informed that their responses would be confidential and did not receive incentives.

\section{Internal Database of Reports}

Data from the CEP's internal management database were analyzed for its first 8 fiscal years (July 2006-June 2014). Variables included requestor characteristics, report characteristics (eg, technology reviewed, clinical specialty examined, completion time, and performance of meta-analyses and GRADE [Grading of Recommendations Assessment, Development and Evaluation] analyses $^{22}$ ), report use (eg, integration of report into CDS interventions) and dissemination beyond the UPHS (eg, submission to Center for Reviews and Dissemination [CRD] Health Technology Assessment [HTA] database $^{23}$ and to peer-reviewed journals). Report completion time was defined as the time between the date work began on the report and the date the final report was sent to the requestor. The technology categorization scheme was adapted from that provided by Goodman $(2004)^{24}$ and the UK National Institute for Health Research HTA Programme. ${ }^{25}$ We systematically assigned the technology reviewed in each report to 1 of 8 mutually exclusive categories. The clinical specialty examined in each report was determined using an algorithm (see Supporting Information, Appendix 1, in the online version of this article).

We compared the report completion times and the proportions of requestor types, technologies reviewed, and clinical specialties examined in the CEP's first 4 fiscal years (July 2006-June 2010) to those in the CEP's second 4 fiscal years (July 2010-June 2014) using $t$ tests and $\chi^{2}$ tests for continuous and categorical variables, respectively.

\section{Survey}

We conducted a Web-based survey (see Supporting Information, Appendix 2, in the online version of this article) of all requestors of the 139 rapid reviews completed in the last 4 fiscal years. Participants who requested multiple reports were surveyed only about the most recent report. Requestors were invited to participate in the survey via e-mail, and follow-up e-mails were sent to nonrespondents at 7, 14, and 16 days. Nonrespondents and respondents were compared with respect to requestor type (physician vs 
Hospital Evidence-Based Practice Centers | Jayakumar et al

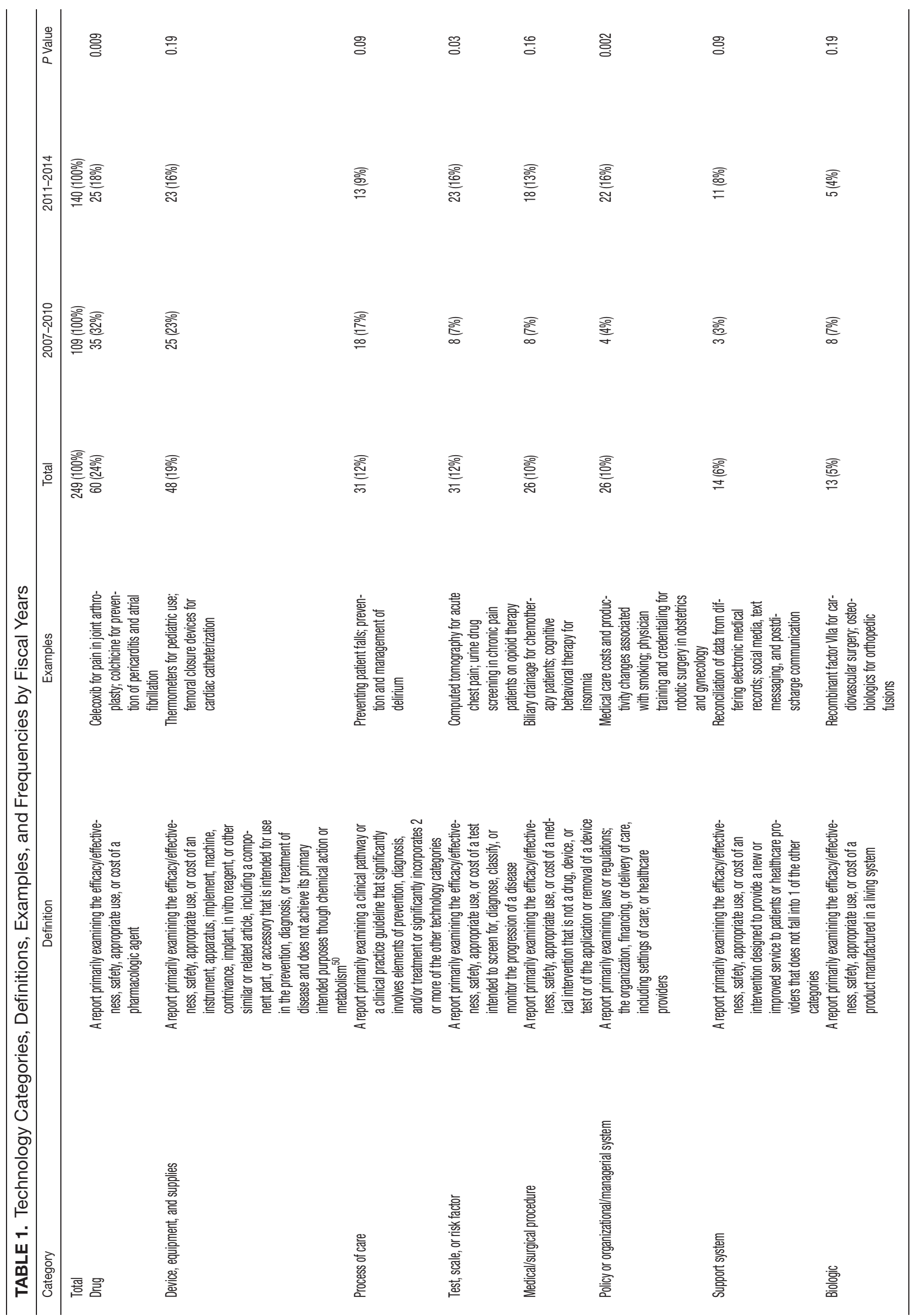


nonphysician) and topic evaluated (traditional HTA topics such as drugs, biologics, and devices vs nontraditional HTA topics such as processes of care). The survey was administered using REDCap ${ }^{26}$ electronic data capture tools. The 44-item questionnaire collected data on the interaction between the requestor and the CEP, report characteristics, report impact, and requestor satisfaction.

Survey results were imported into Microsoft Excel (Microsoft Corp, Redmond, WA) and SPSS (IBM, Armonk, NY) for analysis. Descriptive statistics were generated, and statistical comparisons were conducted using $\chi^{2}$ and Fisher exact tests.

\section{RESULTS}

\section{Evidence Synthesis Activity}

The CEP has produced several different report products since its inception. Evidence reviews $(57 \%, \mathrm{n}=$

\begin{tabular}{|c|c|c|c|c|}
\hline Category & Total & $2007-2010$ & $2011-2014$ & $P$ Value \\
\hline Total & $249(100 \%)$ & $109(100 \%)$ & $140(100 \%)$ & \\
\hline Clinical department & $72(29 \%)$ & $22(20 \%)$ & $50(36 \%)$ & 0.007 \\
\hline CMO & $47(19 \%)$ & $21(19 \%)$ & $26(19 \%)$ & 0.92 \\
\hline Purchasing committee & $35(14 \%)$ & $27(25 \%)$ & $8(6 \%)$ & $<0.001$ \\
\hline Formulary committee & $22(9 \%)$ & $12(11 \%)$ & $10(7 \%)$ & 0.54 \\
\hline Quality committee & $21(8 \%)$ & $11(10 \%)$ & $10(7 \%)$ & 0.42 \\
\hline Administrative department & $19(8 \%)$ & $5(5 \%)$ & $14(10 \%)$ & 0.11 \\
\hline Nursing & $14(6 \%)$ & $4(4 \%)$ & $10(7 \%)$ & 0.23 \\
\hline Other* & $19(8 \%)$ & $7(6 \%)$ & $12(9 \%)$ & 0.55 \\
\hline
\end{tabular}

NOTE: *Other includes ad hoc committees, CEP, Children's Hospital of Philadelphia, IT commintees, payers, and the primary care network.. Abbreviations: CEP, Center for Evidence-based Practice; CMO, chief medical officer; IT, information technology.
142) consist of a systematic review and analysis of the primary literature. Evidence advisories $(32 \%, \mathrm{n}=79)$ are summaries of evidence from secondary sources such as guidelines or systematic reviews. Evidence inventories $(3 \%, \mathrm{n}=7)$ are literature searches that describe the quantity and focus of available evidence, without analysis or synthesis. ${ }^{27}$

The categories of technologies examined, including their definitions and examples, are provided in Table 1. Drugs $(24 \%, \mathrm{n}=60)$ and devices/equipment/ supplies $(19 \%, \mathrm{n}=48)$ were most commonly examined. The proportion of reports examining technology types traditionally evaluated by HTA organizations significantly decreased when comparing the first 4 years of CEP activity to the second 4 years $(62 \%$ vs $38 \%, P<0.01$ ), whereas reports examining less traditionally reviewed categories increased $(38 \%$ vs $62 \%$, $P<0.01)$. The most common clinical specialties represented by the CEP reports were nursing $(11 \%, \mathrm{n}=$ $28)$, general surgery $(11 \%, \mathrm{n}=28)$, critical care $(10 \%, \mathrm{n}=24)$, and general medicine $(9 \%, \mathrm{n}=22)$ (see Supporting Information, Appendix 3, in the online version of this article). Clinical departments were the most common requestors $(29 \%, \mathrm{n}=72)$ (Table 2). The proportion of requests from clinical departments significantly increased when comparing the first 4 years to the second 4 years $(20 \%$ vs $36 \%$, $P<0.01$ ), with requests from purchasing committees significantly decreasing $(25 \%$ vs $6 \%, P<0.01)$. The overall report completion time was 70 days, and significantly decreased when comparing the first 4 years to the second 4 years ( 89 days vs 50 days, $P<0.01$ ).

Thirty-seven $(15 \%)$ reports included meta-analyses conducted by CEP staff. Seventy-five reports $(30 \%)$

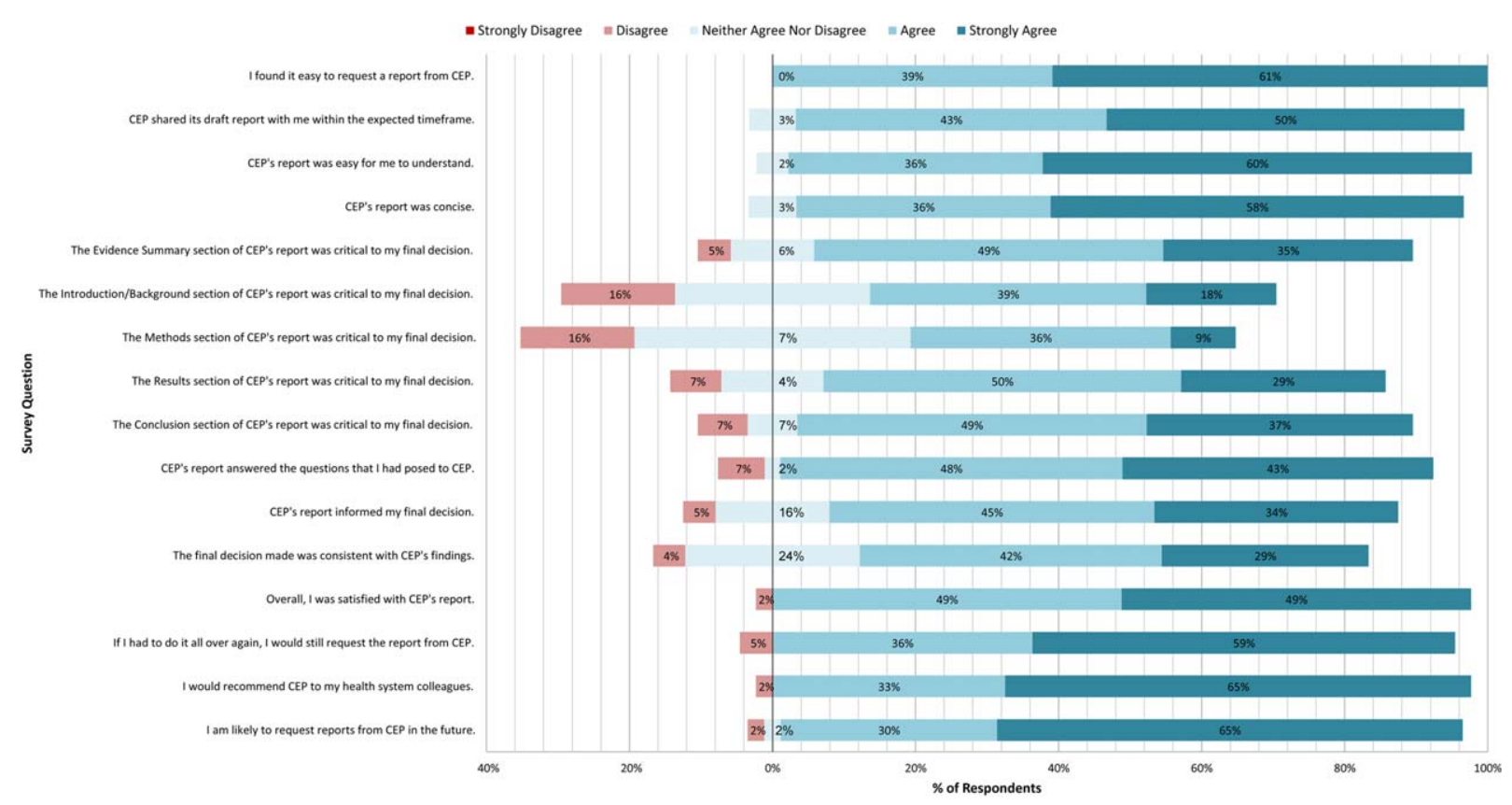

FIG. 1. Requestor responses to Likert survey questions. Abbreviations: CEP, Center for Evidence-based Practice. 
contained an evaluation of the quality of the evidence base using GRADE analyses. ${ }^{22}$ Of these reports, the highest GRADE of evidence available for any comparison of interest was moderate $(35 \%, \mathrm{n}=26)$ or high $(33 \%, \mathrm{n}=25)$ in most cases, followed by very low $(19 \%, \mathrm{n}=14)$ and low $(13 \%, \mathrm{n}=10)$.

Reports were disseminated in a variety of ways beyond direct dissemination and presentation to requestors and posting on the center website. Thirty reports $(12 \%)$ informed CDS interventions, $24(10 \%)$ resulted in peer-reviewed publications, and 204 (82\%) were posted to the CRD HTA database.

\section{Evidence Synthesis Impact}

A total of 139 reports were completed between July 2010 and June 2014 for 65 individual requestors. Email invitations to participate in the survey were sent to the 64 requestors employed by the UPHS. The response rate was $72 \%(46 / 64)$. The proportions of physician requestors and traditional HTA topics evaluated were similar across respondents and nonrespondents $(43 \%$ [20/46] vs $39 \%$ [7/18], $P=0.74$; and $37 \%$ [17/46] vs $44 \%$ [8/18], $P=0.58$, respectively). Aggregated survey responses are presented for items using a Likert scale in Figure 1, and for items using a yes/no or ordinal scale in Table 3.

In general, respondents found reports easy to request, easy to use, timely, and relevant, resulting in high requestor satisfaction. In addition, 98\% described the scope of content and level of detail as "about right." Report impact was rated highly as well, with the "evidence summary" and "conclusions" rated as the most critical to decision making. A majority of respondents indicated that reports confirmed their tentative decision $(77 \%, \mathrm{n}=34)$, whereas some changed their tentative decision $(7 \%, \mathrm{n}=3)$, and others suggested the report had no effect on their tentative decision $(16 \%, \mathrm{n}=7)$. Respondents indicated the amount of time that elapsed between receiving reports and making final decisions was 1 to 7 days $(5 \%, \mathrm{n}=2), 8$ to 30 days $(40 \%, \mathrm{n}=17), 1$ to 3 months $(37 \%, \mathrm{n}=16), 4$ to 6 months $(9 \%, \mathrm{n}=4)$, or greater than 6 months $(9 \%, n=4)$. The most common reasons cited for requesting a report were the CEP's evidence synthesis skills and objectivity.

\section{DISCUSSION}

To our knowledge, this is the first comprehensive description and assessment of evidence synthesis activity by a hospital EPC in the United States. Our findings suggest that clinical and administrative leaders will request reports from a hospital EPC, and that hospital EPCs can promptly produce reports when requested. Moreover, these syntheses can address a wide range of clinical and policy topics, and can be disseminated through a variety of routes. Lastly, requestors are satisfied by these syntheses, and report that they inform decision making. These results
TABLE 3. Responses to Yes/No and Ranking Survey Questions

\begin{tabular}{|c|c|}
\hline Items & $\begin{array}{c}\text { \% of Respondents } \\
\text { Responding Affirmatively }\end{array}$ \\
\hline \multicolumn{2}{|l|}{ Requestor activity } \\
\hline \multicolumn{2}{|l|}{$\begin{array}{l}\text { What factors prompted you to request a report from CEP? } \\
\text { (Please select all that apply.) }\end{array}$} \\
\hline My own time constraints & $28 \%(13 / 46)$ \\
\hline CEP's ability to identify and synthesize evidence & $89 \%(41 / 46)$ \\
\hline CEP's objectivity & $52 \%(24 / 46)$ \\
\hline Recommendation from colleague & $30 \%(14 / 46)$ \\
\hline $\begin{array}{l}\text { Did you conduct any of your own literature searches before } \\
\text { contacting CEP? }\end{array}$ & $67 \%(31 / 46)$ \\
\hline $\begin{array}{l}\text { Did you obtain and read any of the articles cited in CEP's } \\
\text { report? }\end{array}$ & $63 \%(29 / 46)$ \\
\hline \multicolumn{2}{|l|}{ Did you read the following sections of CEP's report? } \\
\hline Evidence summary (at beginning of report) & $100 \%(45 / 45)$ \\
\hline Introduction/background & $93 \%(42 / 45)$ \\
\hline Methods & $84 \%(38 / 45)$ \\
\hline Results & $98 \%(43 / 43)$ \\
\hline Conclusion & $100 \%(43 / 43)$ \\
\hline \multicolumn{2}{|l|}{ Report dissemination } \\
\hline $\begin{array}{l}\text { Did you share CEP's report with anyone NOT involved in } \\
\text { requesting the report or in making the final decision? }\end{array}$ & $67 \%(30 / 45)$ \\
\hline Did you share CEP's report with anyone outside of Penn? & $7 \%(3 / 45)$ \\
\hline \multicolumn{2}{|l|}{ Requestor preferences } \\
\hline $\begin{array}{l}\text { Would it be helpful for CEP staff to call you after you } \\
\text { receive any future CEP reports to answer any questions } \\
\text { you might have? }\end{array}$ & $55 \%(24 / 44)$ \\
\hline \multirow[t]{2}{*}{$\begin{array}{l}\text { Following any future reports you request from CEP, would } \\
\text { you be willing to complete a brief questionnaire? }\end{array}$} & $100 \%(44 / 44)$ \\
\hline & $\begin{array}{l}\text { Percentage of Respondents } \\
\text { Ranking as First Choice }\end{array}$ \\
\hline \multicolumn{2}{|l|}{$\begin{array}{l}\text { Please rank how you would prefer to receive reports from } \\
\text { CEP in the future. }\end{array}$} \\
\hline E-mail containing the report as a PDF attachment & $77 \%(34 / 44)$ \\
\hline E-mail containing a link to the report on CEP's website & $16 \%(7 / 44)$ \\
\hline $\begin{array}{l}\text { In-person presentation by the CEP analyst writing the } \\
\text { report }\end{array}$ & $18 \%(8 / 44)$ \\
\hline $\begin{array}{l}\text { In-person presentation by the CEP director involved in the } \\
\text { report }\end{array}$ & $16 \%(7 / 44)$ \\
\hline
\end{tabular}

NOTE: Abbreviations: CEP, Center for Evidence-based Practice. ${ }^{*}$ The sum of these percentages is greater than 100 percent because respondents could rank multiple options first.

suggest that EPCs may be an effective infrastructure paradigm for promoting evidence-based decision making within healthcare provider organizations, and are consistent with previous analyses of hospital-based EPCs. ${ }^{21,28,29}$

Over half of report requestors cited CEP's objectivity as a factor in their decision to request a report, underscoring the value of a neutral entity in an environment where clinical departments and hospital committees may have competing interests. ${ }^{10}$ This asset was 1 of the primary drivers for establishing our hospital EPC. Concerns by clinical executives about the influence of industry and local politics on institutional decision making, and a desire to have clinical evidence more systematically and objectively integrated into decision making, fueled our center's funding. 
The survey results also demonstrate that respondents were satisfied with the reports for many reasons, including readability, concision, timeliness, scope, and content, consistent with the evaluation of the French hospital-based EPC CEDIT (French Committee for the Assessment and Dissemination of Technological Innovations). ${ }^{29}$ Given the importance of readability, concision, and relevance that has been previously described, ${ }^{16,28,30}$ nearly all CEP reports contain an "evidence summary" on the first page that highlights key findings in a concise, user-friendly format. ${ }^{31}$ The evidence summaries include bullet points that: (1) reference the most pertinent guideline recommendations along with their strength of recommendation and underlying quality of evidence; (2) organize and summarize study findings using the most critical clinical outcomes, including an assessment of the quality of the underlying evidence for each outcome; and (3) note important limitations of the findings.

Evidence syntheses must be timely to allow decision makers to act on the findings. ${ }^{28,32}$ The primary criticism of CEDIT was the lag between requests and report publication. ${ }^{29}$ Rapid reviews, designed to inform urgent decisions, can overcome this challenge. ${ }^{31,33,34}$ CEP reviews required approximately 2 months to complete on average, consistent with the most rapid timelines reported, ${ }^{31,33,34}$ and much shorter than standard systematic review timelines, which can take up to 12 to 24 months. ${ }^{33}$ Working with requestors to limit the scope of reviews to those issues most critical to a decision, using secondary resources when available, and hiring experienced research analysts help achieve these efficiencies.

The study by Bodeau-Livinec also argues for the importance of report accessibility to ensure dissemination. ${ }^{29}$ This is consistent with the CEP's approach, where all reports are posted on the UPHS internal website. Many also inform QI initiatives, as well as CDS interventions that address topics of general interest to acute care hospitals, such as venous thromboembolism (VTE) prophylaxis, ${ }^{35}$ blood product transfusions, ${ }^{36}$ sepsis care, ${ }^{37,38}$ and prevention of catheter-associated urinary tract infections (CAUTI) ${ }^{39}$ and hospital readmissions. ${ }^{40}$ Most reports are also listed in an international database of rapid reviews, ${ }^{23}$ and reports that address topics of general interest, have sufficient evidence to synthesize, and have no prior published systematic reviews are published in the peer-reviewed literature. ${ }^{41,42}$

The majority of reports completed by the CEP were "evidence reviews," or systematic reviews of primary literature, suggesting that CEP reports often address questions previously unanswered by existing published systematic reviews; however, about a third of reports were "evidence advisories," or summaries of evidence from preexisting secondary sources. The relative scarcity of high-quality evidence bases in those reports where GRADE analyses were conducted might be expected, as requestors may be more likely to seek guidance when the evidence base on a topic is lacking. This was further supported by the small percentage $(15 \%)$ of reports where adequate data of sufficient homogeneity existed to allow meta-analyses. The small number of original meta-analyses performed also reflects our reliance on secondary resources when available.

Only $7 \%$ of respondents reported that tentative decisions were "changed" based on their report. This is not surprising, as evidence reviews infrequently result in clear "go" or "no go" recommendations. More commonly, they address or inform complex clinical questions or pathways. In this context, the "change/ confirm/no effect" framework may not completely reflect respondents' use of or benefit from reports. Thus, we included a diverse set of questions in our survey to best estimate the value of our reports. For example, when asked whether the report answered the question posed, informed their final decision, or was consistent with their final decision, $91 \%, 79 \%$, and $71 \%$ "agreed" or "strongly agreed," respectively. When asked whether they would request a report again if they had to do it all over, recommend CEP to their colleagues, and be likely to request reports in the future, at least $95 \%$ of survey respondents "agreed" or "strongly agreed." In addition, no respondent indicated that their report was not timely enough to influence their decision. Moreover, only a minority of respondents expressed disappointment that the CEP's report did not provide actionable recommendations due to a lack of published evidence $(9 \%, n=4)$. Importantly, the large proportion of requestors indicating that reports confirmed their tentative decisions may be a reflection of "hindsight bias."

The most apparent trend in the production of CEP reviews over time is the relative increase in requests by clinical departments, suggesting that the CEP is being increasingly consulted to help define best clinical practices. This is also supported by the relative increase in reports focused on policy or organizational/managerial systems. These findings suggest that hospital EPCs have value beyond the traditional realm of HTA.

This study has a number of limitations. First, not all of the eligible report requestors responded to our survey. Despite this, our response rate of $72 \%$ compares favorably with surveys published in medical journals. ${ }^{43}$ In addition, nonresponse bias may be less important in physician surveys than surveys of the general population. ${ }^{44}$ The similarity in requestor and report characteristics for respondents and nonrespondents supports this. Second, our survey of impact is self-reported rather than an evaluation of actual decision making or patient outcomes. Thus, the survey relies on the accuracy of the responses. Third, recall bias must be considered, as some respondents were asked to evaluate reports that were greater than 1 year old. To reduce this bias, we asked respondents to consider the most recent report they requested, 
included that report as an attachment in the survey request, and only surveyed requestors from the most recent 4 of the CEP's 8 fiscal years. Fourth, social desirability bias could have also affected the survey responses, though it was likely minimized by the promise of confidentiality. Fifth, an examination of the impact of the CEP on costs was outside the scope of this evaluation; however, such information may be important to those assessing the sustainability or return on investment of such centers. Simple approaches we have previously used to approximate the value of our activities include: (1) estimating hospital cost savings resulting from decisions supported by our reports, such as the use of technologies like chlorhexidine for surgical site infections ${ }^{45}$ or discontinuation of technologies like aprotinin for cardiac surgery ${ }^{46}$; and (2) estimating penalties avoided or rewards attained as a result of center-led initiatives, such as those to increase VTE prophylaxis, ${ }^{35}$ reduce CAUTI rates, ${ }^{39}$ and reduce preventable mortality associated with sepsis. ${ }^{37,38}$ Similarly, given the focus of this study on the local evidence synthesis activities of our center, our examination did not include a detailed description of our CDS activities, or teaching activities, including our multidisciplinary workshops for physicians and nurses in evidence-based $\mathrm{QI}^{47}$ and our novel evidence-based practice curriculum for medical students. Our study also did not include a description of our extramural activities, such as those supported by our contract with AHRQ as 1 of their 13 EPCs. ${ }^{16,17,48,49}$ A consideration of all of these activities enables a greater appreciation for the potential of such centers. Lastly, we examined a single EPC, which may not be representative of the diversity of hospitals and hospital staff across the United States. However, our EPC serves a diverse array of patient populations, clinical services, and service models throughout our multientity academic healthcare system, which may improve the generalizability of our experience to other settings.

As next steps, we recommend evaluation of other existing hospital EPCs nationally. Such studies could help hospitals and health systems ascertain which of their internal decisions might benefit from locally sourced rapid systematic reviews and determine whether an in-house EPC could improve the value of care delivered.

In conclusion, our findings suggest that hospital EPCs within academic healthcare systems can efficiently synthesize and disseminate evidence for a variety of stakeholders. Moreover, these syntheses impact decision making in a variety of hospital contexts and clinical specialties. Hospitals and hospitalist leaders seeking to improve the implementation of evidencebased practice at a systems level might consider establishing such infrastructure locally.

\section{Acknowledgements}

The authors thank Fran Barg, PhD (Department of Family Medicine and Community Health, University of Pennsylvania Perelman School of
Medicine) and Joel Betesh, MD (University of Pennsylvania Health System) for their contributions to developing the survey. They did not receive any compensation for their contributions.

Disclosures: An earlier version of this work was presented as a poster at the 2014 AMA Research Symposium, November 7, 2014, Dallas, Texas. Mr. Jayakumar reports having received a University of Pennsylvania fellowship as a summer intern at the Center for Evidence-based Practice. Dr. Umscheid cocreated and directs a hospital evidence-based practice center, is the Senior Associate Director of an Agency for Healthcare Research and Quality Evidence-Based Practice Center, and is a past member of the Medicare Evidence Development and Coverage Advisory Committee, which uses evidence reports developed by the Evidencebased Practice Centers of the Agency for Healthcare Research and Quality. Dr. Umscheid's contribution was supported in part by the National Center for Research Resources, grant UL1RR024134, which is now at the National Center for Advancing Translational Sciences, grant UL1TR000003. The content of this article is solely the responsibility of the authors and does not necessarily represent the official views of the National Institutes of Health. None of the funders had a role in the design and conduct of the study; collection, management, analysis, and interpretation of the data; preparation, review, or approval of the manuscript; and decision to submit the manuscript for publication. Dr. Lavenberg, Dr. Mitchell, and Mr. Leas are employed as research analysts by a hospital evidence-based practice center. Dr. Doshi is supported in part by a hospital evidence-based practice center and is an Associate Director of an Agency for Healthcare Research and Quality Evidence-based Practice Center. Dr. Goldmann is emeritus faculty at Penn, is supported in part by a hospital evidence-based practice center, and is the Vice President and Chief Quality Assurance Officer in Clinical Solutions, a division of Elsevier, Inc., a global publishing company, and director of the division's Evidence-based Medicine Center. Dr. Williams cocreated and codirects a hospital evidence-based practice center. Dr. Brennan has oversight for and helped create a hospital evidence-based practice center.

\section{References}

1. Avorn J, Fischer M. "Bench to behavior": translating comparative effectiveness research into improved clinical practice. Health Aff (Millwood). 2010;29(10):1891-1900.

2. Rajab MH, Villamaria FJ, Rohack JJ. Evaluating the status of "translating research into practice" at a major academic healthcare system. Int J Technol Assess Health Care. 2009;25(1):84-89.

3. Timbie JW, Fox DS, Van Busum K, Schneider EC. Five reasons that many comparative effectiveness studies fail to change patient care and clinical practice. Health Aff (Millwood). 2012;31(10):2168-2175.

4. Damschroder LJ, Aron DC, Keith RE, Kirsh SR, Alexander JA, Lowery JC. Fostering implementation of health services research findings into practice: a consolidated framework for advancing implementation science. Implement Sci. 2009;4(1):50.

5. Grol R, Grimshaw J. From best evidence to best practice: effective implementation of change in patients' care. Lancet. 2003;362(9391): $1225-1230$.

6. Umscheid CA, Brennan PJ. Incentivizing "structures" over "outcomes" to bridge the knowing-doing gap. JAMA Intern Med. 2015;175(3):354.

7. Olsen L, Aisner D, McGinnis JM, eds. Institute of Medicine (US) Roundtable on Evidence-Based Medicine. The Learning Healthcare System: Workshop Summary. Washington, DC: National Academies Press; 2007. Available at: http://www.ncbi.nlm.nih.gov/books/ NBK53494/. Accessed October 29, 2014.

8. Harrison MB, Legare F, Graham ID, Fervers B. Adapting clinical practice guidelines to local context and assessing barriers to their use. Can Med Assoc J. 2010;182(2):E78-E84.

9. Mitchell MD, Williams K, Brennan PJ, Umscheid CA. Integrating local data into hospital-based healthcare technology assessment: two case studies. Int I Technol Assess Health Care. 2010;26(3):294-300.

10. Umscheid CA, Williams K, Brennan PJ. Hospital-based comparative effectiveness centers: translating research into practice to improve the quality, safety and value of patient care. J Gen Intern Med. 2010; 25(12):1352-1355.

11. Gutowski C, Maa J, Hoo KS, Bozic KJ, Bozic K. Health technology assessment at the University of California-San Francisco. I Healthc Manag Am Coll Healthc Exec. 2011;56(1):15-29; discussion 29-30

12. Schottinger J, Odell RM. Kaiser Permanente Southern California regional technology management process: evidence-based medicine operationalized. Perm J. 2006;10(1):38-41.

13. Gagnon M-P. Hospital-based health technology assessment: developments to date. Pharmacoeconomics. 2014;32(9):819-824.

14. Cicchetti A, Marchetti M, Dibidino R, Corio M. Hospital based health technology assessment world-wide survey. Available at: http:// www.htai.org/fileadmin/HTAi_Files/ISG/HospitalBasedHTA/2008Files/ HospitalBasedHTAISGSurveyReport.pdf. Accessed October 11, 2015. 
15. Stevens AJ, Longson C. At the center of health care policy making: the use of health technology assessment at NICE. Med Decis Making. 2013;33(3):320-324.

16. Atkins D, Fink K, Slutsky J. Better information for better health care: the Evidence-based Practice Center program and the Agency for Healthcare Research and Quality. Ann Intern Med. 2005;142(12 part 2):1035-1041.

17. Slutsky JR, Clancy CM. AHRQ's Effective Health Care Program: why comparative effectiveness matters. Am J Med Qual. 2009;24(1):6770 .

18. Grimshaw JM, Russell IT. Effect of clinical guidelines on medical practice: a systematic review of rigorous evaluations. Lancet. 1993; 342(8883):1317-1322.

19. Graham ID, Logan J, Harrison MB, et al. Lost in knowledge translation: time for a map? J Contin Educ Health Prof. 2006;26(1):13-24.

20. Gagnon M-P, Desmartis M, Poder T, Witteman W. Effects and repercussions of local/hospital-based health technology assessment (HTA): a systematic. Syst Rev. 2014;3:129.

21. McGregor M, Arnoldo J, Barkun J, et al. Impact of TAU Reports. McGill University Health Centre. Available at: https://francais.mcgill. ca/files/tau/FINAL_TAU_IMPACT_REPORT_FEB_2008.pdf. Published Feb 1, 2008. Accessed August 19, 2014.

22. Guyatt GH, Oxman AD, Vist GE, et al. GRADE: an emerging consensus on rating quality of evidence and strength of recommendations. BMJ. 2008;336(7650):924-926.

23. Booth AM, Wright KE, Outhwaite H. Centre for Reviews and Dissemination databases: value, content, and developments. Int J Technol Assess Health Care. 2010;26(4):470-472.

24. Goodman C. HTA 101. Introduction to Health Technology Assessment. Available at: https://www.nlm.nih.gov/nichsr/hta101/ta10103. html. Accessed October 11, 2015.

25. National Institute for Health Research. Remit. NIHR HTA Programme. Available at: http://www.nets.nihr.ac.uk/programmes/hta/ remit. Accessed August 20, 2014.

26. Harris PA, Taylor R, Thielke R, Payne J, Gonzalez N, Conde JG. Research Electronic Data Capture (REDCap)—a metadata-driven methodology and workflow process for providing translational research informatics support. J Biomed Inform. 2009;42(2):377-381.

27. Mitchell MD, Williams K, Kuntz G, Umscheid CA. When the decision is what to decide: Using evidence inventory reports to focus health technology assessments. Int J Technol Assess Health Care. 2011; 27(2):127-132.

28. McGregor M, Brophy JM. End-user involvement in health technology assessment (HTA) development: a way to increase impact. Int J Technol Assess Health Care. 2005;21(02):263-267.

29. Bodeau-Livinec F, Simon E, Montagnier-Petrissans C, Joël M-E, FéryLemonnier E. Impact of CEDIT recommendations: an example of health technology assessment in a hospital network. Int J Technol Assess Health Care. 2006;22(2):161-168.

30. Alexander JA, Hearld LR, Jiang HJ, Fraser I. Increasing the relevance of research to health care managers: hospital CEO imperatives for improving quality and lowering costs. Health Care Manage Rev. 2007;32(2):150-159.

31. Khangura S, Konnyu K, Cushman R, Grimshaw J, Moher D. Evidence summaries: the evolution of a rapid review approach. Syst Rev. 2012; $1(1): 10$.

32. Brown M, Hurwitz J, Brixner D, Malone DC. Health care decision makers' use of comparative effectiveness research: report from a series of focus groups. J Manag Care Pharm. 2013;19(9):745-754.

33. Watt A, Cameron A, Sturm L, et al. Rapid reviews versus full systematic reviews: an inventory of current methods and practice in health technology assessment. Int J Technol Assess Health Care. 2008;24(2): $133-139$.

34. Hartling L, Guise J-M, Kato E, et al. EPC Methods: An Exploration of Methods and Context for the Production of Rapid Reviews. Rockville, MD: Agency for Healthcare Research and Quality; 2015. Available at: http://www.ncbi.nlm.nih.gov/books/NBK274092. Accessed March 5, 2015.

35. Umscheid CA, Hanish A, Chittams J, Weiner MG, Hecht TEH. Effectiveness of a novel and scalable clinical decision support intervention to improve venous thromboembolism prophylaxis: a quasiexperimental study. BMC Med Inform Decis Mak. 2012;12:92.

36. McGreevey JD. Order sets in electronic health records: principles of good practice. Chest. 2013;143(1):228-235.

37. Umscheid CA, Betesh J, VanZandbergen C, et al. Development, implementation, and impact of an automated early warning and response system for sepsis. J Hosp Med. 2015;10(1):26-31.

38. Guidi JL, Clark K, Upton MT, et al. Clinician perception of the effectiveness of an automated early warning and response system for sepsis in an academic medical center. Ann Am Thorac Soc. 2015;12(10): 1514-1519.

39. Baillie CA, Epps M, Hanish A, Fishman NO, French B, Umscheid CA. Usability and impact of a computerized clinical decision support intervention designed to reduce urinary catheter utilization and catheterassociated urinary tract infections. Infect Control Hosp Epidemiol. 2014;35(9):1147-1155.

40. Baillie CA, VanZandbergen C, Tait G, et al. The readmission risk flag: using the electronic health record to automatically identify patients at risk for 30-day readmission. I Hosp Med. 2013;8(12):689-695.

41. Mitchell MD, Mikkelsen ME, Umscheid CA, Lee I, Fuchs BD, Halpern SD. A systematic review to inform institutional decisions about the use of extracorporeal membrane oxygenation during the H1N1 influenza pandemic. Crit Care Med. 2010;38(6):1398-1404.

42. Mitchell MD, Anderson BJ, Williams K, Umscheid CA. Heparin flushing and other interventions to maintain patency of central venous catheters: a systematic review. J Adv Nurs. 2009;65(10):2007-2021.

43. Asch DA, Jedrziewski MK, Christakis NA. Response rates to mail surveys published in medical journals. J Clin Epidemiol. 1997;50(10): 1129-1136.

44. Kellerman SE, Herold J. Physician response to surveys: a review of the literature. Am J Prev Med. 2001;20(1):61-67.

45. Lee I, Agarwal RK, Lee BY, Fishman NO, Umscheid CA. Systematic review and cost analysis comparing use of chlorhexidine with use of iodine for preoperative skin antisepsis to prevent surgical site infection. Infect Control Hosp Epidemiol. 2010;31(12):1219-1229.

46. Umscheid CA, Kohl BA, Williams K. Antifibrinolytic use in adult cardiac surgery. Curr Opin Hematol. 2007;14(5):455-467.

47. Wyer PC, Umscheid CA, Wright S, Silva SA, Lang E. Teaching evidence assimilation for collaborative health care (TEACH) 2009-2014: building evidence-based capacity within health care provider organizations. EGEMS (Wash DC). 2015;3(2):1165.

48. Han JH, Sullivan N, Leas BF, Pegues DA, Kaczmarek JL, Umscheid CA. Cleaning hospital room surfaces to prevent health care-associated infections: a technical brief [published online August 11, 2015]. Ann Intern Med. doi:10.7326/M15-1192.

49. Umscheid CA, Agarwal RK, Brennan PJ, Healthcare Infection Control Practices Advisory Committee. Updating the guideline development methodology of the Healthcare Infection Control Practices Advisory Committee (HICPAC). Am I Infect Control. 2010;38(4):264-273.

50. U.S. Food and Drug Administration. FDA basics-What is a medical device? Available at: http://www.fda.gov/AboutFDA/Transparency/ Basics/ucm211822.htm. Accessed November 12, 2014. 